\title{
CROWDSOURCING AND SERVICE-DOMINANT LOGIC: THE INTERACTION EFFECT OF BRAND FAMILIARITY, CUSTOMER EXPERIENCE AND LOYALTY ON VALUE CO-CREATION
}

\author{
Cheah Wen Kita, Izzal Asnira Zolkepli (Ph.D) ${ }^{\mathrm{b}}$ \\ a Inceptale Media, Kuala Lumpur, Malaysia \\ b Universiti Sains Malaysia, Penang, Malaysia \\ Corresponding email: cheah@inceptale.com
}

\begin{abstract}
Crowdsourcing is a process that enables firms to tap into the wisdom of the crowds or customers to create ideas and solve problems through value co-creation. Utilizing the idea of crowdsourcing, this research was designed using Service-Dominant (SD) Logic that suggests brand familiarity and levels of involvement of co-creators determine the success of value cocreation. Therefore, this research was conducted to investigate the interaction effects between two factors that is customer experience and loyalty. A 3x2 between-subjects factorial design was conducted using online experiment to test the hypotheses. 96 participants were asked to choose one of the six experimental conditions that required them to co-create a pizza menu for a brand. Two-way analysis of covariance (ANCOVA) was used to analyse the collected data on experience and loyalty shared by the participants. The results showed significant effect on the interaction of both variables on pragmatic experience. The result suggests that customers' pragmatic experience needs to be met in order to achieve the success desired. The present study contributes to a wealth of knowledge in the emerging field of service marketing, mainly in the application of crowdsourcing and the understanding of SD Logic.
\end{abstract}

Keywords: Crowdsourcing, Value Co-Creation, Brand Familiarity, Service-Dominant Logic, ANCOVA.

\section{Introduction}

In the present dynamic and interconnected economy, firms are leveraging on the concept of crowdsourcing to generate new ideas and solve problems (Kristal, et al., 2016). As firms are shifting towards customer-centric (Zolkepli, 2016), marketers are recognising the role of customer in creating value via co-creation (Hansen, 2017). To do so, firms initiate crowd sourcing in order to achieve value co-creation, that can be referred to as the process of involving two or more parties working together to reach common desired outcomes by sharing values, resources and intelligence (Kennedy \& Guzman, 2016). Crowdsourcing thereby enables firms to streamline strategies which allow them to connect with a wide network of target markets and mobilise growth. In this sense also, firms are able to receive higher engagement from social media and other virtual platforms participation which has been made possible by web 3.0 to support the business in numerous ways and in cost effective manner (Maddux \& Johnson, 2012; Zolkepli, 2016). The essence of this is that firms can tap into the wisdom of the crowd in co-creating a solution, thus leading to more understanding on consumer endless demand and evolving behavior (Lee et al., 2015; Zolkepli, 2016).

In the process of designing the idea and development of value co-creation, the overall experiences of the co-creators will need to be taken into consideration so as to increase the 
chances of them returning as loyal customers once they have gained positive experience from the co-creation process holistically (Verleye, 2015; Vargo \& Lusch, 2004). Value co-creation is impactful increasing stronger engagement that leads to positive customer experience and loyalty, where through this it forms a strong brand community (Muniz \& O'Guinn, 2001; Stokburger-Sauer et al., 2016; Adrine \& Solem, 2016; Li, Tang, \& Zhou, 2015; Jahn \& Kunz, 2012; Oyner \& Korelina, 2016).

However, value co-creation is arguably influenced by customers' familiarity with the involved brand. It is an occurrence to witness unfamiliar brand to fail in a crowdsourcing engagement activity as customers are skeptical to impart their effort, resources, and values with the unknown brands (France, Merrilees, \& Miller 2015). Thus, it would be a challenge for an unfamiliar brand to co-create product, service and value with the help of the customers. In this stage, brand knowledge is critical in influencing the behavioral response of the consumer (Aaker, 1997). With lack of brand knowledge, it would be unfair for the new businesses like small-medium enterprise (SME)that are small in the market to get high involvement in co-creation process. Van Dijk, Antonides, \& Schlillewaert (2014) have highlighted that familiar brands have a positive impact in creating values as they have formed certain brand associations prior to it. It is a challenge for an unfamiliar brand to accomplish value co-creation.

In the field of value co-creation, this issue needs to be addressed as empirical findings are rather scarce (Carbonell, Rodriguez-Escuardo, \&Pujari, 2009). Therefore, the objective of this study is:

(i) To investigate the effect of brand familiarity and the levels of co-creation involvement on customer experience and customer loyalty; and

(ii) To investigate the dimensions of customer experience that is most affected by the intervention of brand familiarity on the levels of value co-creation in the context of crowdsourcing engagement.

This research contributes towards the building blocks of value co-creation in the scope of brand familiarity and the levels of co-creation involvement in crowdsourcing engagement that serve as a guiding framework based on the wealth of Service-Dominant (SD) Logic.

\section{Service Dominant (SD) Logic}

The concept of value co-creation is built on the foundation of the revolutionary frontier in marketing called Service Dominant (SD) Logic, which explains that for businesses to thrive, firms should focus on delivering values and services instead of the tangible products or goods (Vargo \& Lusch, 2004; Groonroos, 2006; Saarijarvi Kannan, \& Kuusela, 2013).SD Logic derives from the idea that service is uniquely exclusive from the production of goods (Vargo \& Lusch, 2004; Groonroos, 2006; Hansen, 2017). It ties numerous loose ends that conservatively look at the tangible aspects of product offerings as Vargo and Lusch (2004) refer it as Goods-Dominant (GD) Logic. Hence, SD Logic is a transcendence of GD logic. It extends the perspective of values and services delivered by the firms to the values delivered by the customers (Saarivarji et al., 2013).Vargo and Lusch (2008) define "service" as the application of competence that include knowledge and skills in benefiting the receiving end of the products, it does not matter whether the firm is delivering goods-based (tangible) or serviced-based (intangible) business as service is not the output, but rather the process of trade (Hansen, 2017). SD Logic argues that service should be the units of exchange, whereas goods are only the mediator or transmitter of trade (Vargo \& Lusch, 2008; Saarivarji et al., 2013). As service is viewed as interactional in a business process, its domain is meant as a form of logic that builds on four axioms, which are: i) service as the vital foundation of exchange, ii) customers are always the value co-creators, iii) all industry players in the realm of social and economic are the resource integrators, and iv) value is determined by the recipient or beneficiary in phenomenological sense (Saarivarji et al., 2013; McColl-Kennedy, Cheung, \& Ferrier, 2015). In-line with recent marketing development, customer-centric 
firms in the present age are seeking novel and better ways to generate value for customers, especially to deliver desirable experience and generate loyalty for their stakeholders(VegaVazquez, Revilla-Camacho, \& Cossio-Silva, 2013).Value creation is a joint function between the provider and receiver, which makes it co-created all the time (Saarivarji et al., 2013).

Value co-creation concept that is initiated by a firm involves bi-lateral communication, which is an initiator (also referred as the actor) who is looking for new ideas or solve problems, that needs to be reciprocated by the intended customers who are willing to contribute (Bauer \& Gegenhuber, 2015). In this perspective, value co-creation is considered a situation that makes it possible for both parties to achieve an increased value through a collaboration process (Vargo, Maglio, \& Akaka 2008; Vega-Vasquez et al., 2013). In order to ask for the people to carry out the intended task, the actor will initiate an open call using crowdsourcing approach (Howe, 2006). Crowdsourcing enables the firms to tap into the wisdom of the crowd to co-create solutions and innovations (Brabham, 2008; Marjanovic, Fry, \& Chataway, 2012; Majchrzak \& Malhotra, 2013; Agafonovas \& Alonderien, 2013). As past researches suggest that the success of crowdsourcing depends on brand familiarity of the initator, understanding the effect of it would help companies to design a more impactful approach.

\section{Brand Familiarity}

$\mathrm{Xu}$, Ribeiro-Soriano and Gonzalez-Garcia (2015) argued that brands that use the concept of co-creation effectively perform better than the ones that do not. Familiarity with a brand is found to influence the success in performing product-related tasks. As a person possesses knowledge about a brand, it is more likely for the individual to perform specific task related to the brand (Kristal et al., 2016; Jacoby et al., 1986; Alba \& Hutchinson, 1987). Brand familiarity is regarded as the collected experience that a person has had with a brand (Tam, 2008). Lin (2013) explained that the relevant factors in forming one's experiences include the individual's previous exposure, information search, the word-of-mouth (WOM) communication that he or she received and the consumption of product with the brand. The knowledge could be derived from advertising, purchasing, or exposure through other relevant touchpoints such as through interaction with the sales personnel (Jacoby et al. 1986).

A study that was done by Tam (2008) showed that brand familiarity affects the formation of satisfaction and post-purchase intentions. The more familiar a person has with the brand, the greater the ability a person will be in performing the task (Alba \& Hutchinson, 1987; Ericsson \& Smith, 1991). Such understanding implies that if a person is asked to involve in a co-creation activity by a brand, the person is able to carry out the task well. A co-creation study by Kristal et al. (2016) in observer-based brand equity (OBBE) proves such argument to be valid. OBBE is referred to the brand equity perceived by the consumer who are merely the observer of a brand or one who is exposed to a particular brand, but may not be a user yet (Kristal et al. 2016). While co-creation is not a new concept, firms are now realising the potential of this approach as they are sharing the control of their brand identity (Kennedy \& Guzman, 2016) and brand equity (Kristal et al., 2016) with the target market. Firms have been finding ways to get their customers in building their brands. The conventional innovation approach that merely views consumers as passive entity is changing towards active contributor that satisfies the firms' objectives.

With the aggressive development of technology pertaining to social media and strong dependency of the society on the world wide web, co-creation is further enhanced as a growing number of firms are beginning to realise the potential of this approach for their business success. McDonald's have carried a co-creation campaign in Germany that helped them to generate approximately 116,000 new burger recipes (Kristal et al., 2016). The campaign has generated about 1.5 million observers to register themselves to be part of the customer engagement approach by registering and voting for their favourite burgers submitted by the co-creators through their Facebook page. Another successful value co- 
creation approach was witnessed in an unknown fashion brand called Threadless. The company has built their business by asking online users to co-create a t-shirt design that will be sold to other customers. It is suggested that unfamiliar brand's success depends on the experience that they are able to create.

\section{Experience and Loyalty}

In value co-creation, customer experience is considered as one of the key concepts in marketing as it influences loyalty (Vega-Vazquez et al., 2013; Verleye, 2015; Oyner \& Korelina, 2016). In the context of co-creation, the complexity of customer satisfaction is even more apparent as the overall experience is determined by several dimensions such as hedonic, cognitive, social, personal, pragmatic and economic experience (Verleye, 2015). These dimensions would contribute to the overall experience associated with the brand that performs a co-creation approach. As summarised by Verleye (2015), Hedonic experience refers to the pleasurable involvement from the co-creation activity. Cognitive experience refers to the condition that gaining new knowledge as essential in ensuring the success of the co-creation activity. In addition, customers would enjoy connecting with other people in a co-creation activity, which Verleye (2015) mentioned as the social experience. It is also argued that an individual enjoys having recognition from a co-creation activity, which is referred to as the personal experience by Verleye (2015). Pragmatic experience refers to the point that it is important for a customer to meet their personal needs. It is also argued that customers expect to be rewarded and compensated for the effort that they have made, which is referred to as the economic benefits. From the firm owner's perspective to focus on customer-centric approach, the concept of co-creation would be advantageous to create value for the business.

While Verleye (2015) has found that high level of co-creation involvement would contribute towards overall co-creation on customer experience, Stokburger-Sauer et al. (2016) proved otherwise by reporting that the levels of involvement in co-creation play an important role. It was found that low and high customer involvement negatively impact the intended result of customer experience and loyalty, whereas the optimum result is achieved through medium involvement (Stokburger-Sauer et al., 2016). Meanwhile, Homburg and Kuehnl (2014) raises the concern on whether greater contribution would produce better outcomes. In support of this, Stokburger-Sauer et al. (2016) demonstrated that the increasing involvement of customers in a co-creation approach does not necessarily mean that they have greater loyalty to the brand. The sharing of values requires the co-creators to impart their resources of time, knowledge and energy that could lead to a certain degree of experience and loyalty. Beyond the optimum level of co-creation, the assessment or intention to stay loyal to the initiator or actor would diminish.

Having to say that, one of the contributing factors towards experience and loyalty is contact interactivity, which refers to the two-way communication of engagement between firms and customers (Srivivasan, Anderson, \& Ponnavolu, 2002). However, it is argued that greater engagement does not necessarily translate to customer loyalty (Homburg \& Kuehnl, 2014; Stokburger-Sauer et al., 2016). Thus, for this research it is hypothesised that:

H1: There is a main effect of the levels of involvement in value co-creation and brand familiarity on hedonic customer experience.

H2: There is a main effect of the levels of involvement in value co-creation and brand familiarity on cognitive customer experience.

H3: There is a main effect of the levels of involvement in value co-creation and brand familiarity on social customer experience.

H4: There is a main effect of the levels of involvement in value co-creation and brand familiarity on personal customer experience. 
$\mathrm{H}_{5}$ : There is a main effect of the levels of involvement in value co-creation and brand familiarity on pragmatic customer experience.

H6: There is a main effect of the levels of involvement in value co-creation and brand familiarity on economic customer experience

H7: There is a main effect of the levels of involvement in value co-creation and brand familiarity on customer loyalty.

\section{Methodology \\ 5.1 Design and Sampling}

A 3x2 between subjects factorial design was conducted using an online experiment in order to investigate the effects of brand familiarity and the levels of co-creation involvement on the dimensions of customer experience and loyalty. Male and female participants aged 18 to 64 who reside in Malaysia were recruited through dedicated website.

\subsection{Instrumentation and the Measurement of Constructs}

The study is conducted in Malaysia, a well-known F\&B brand in the local sector called Domino's Pizza is used as familiar brand. As for the non-familiar brand, Pizza Delight was used as it is unfamiliar by the local consumers. There were six experimental conditions involved in the present study, which were 1) Familiar brand and low co-creation involvement, 2) Familiar brand and medium co-creation involvement, 3) Familiar brand and high co-creation involvement, 4) Unfamiliar brand and low co-creation involvement, 5) Unfamiliar brand and medium co-creation involvement, and 6) Unfamiliar brand and high co-creation involvement. Participants who chose one of the six experimental conditions were required to hypothetically co-create a pizza menu, which the level of involvement were manipulated based on the degree of difficulty and time to complete. Thereafter, they were given a self-reported questionnaire that measured their experience and loyalty as adapted from Stokburger et al. (2016) and Verleye (2015). A Reliability test was also conducted to ensure that the items are reliable to be used for further analysis. Inter-item consistency was analysed to determine if all the items in each of the variables are measuring the same construct. The items that were identified as having less correlation were omitted for further analysis.

\section{Findings}

\subsection{Descriptive Analysis}

With the total number of groups in the study is set at 6 experimental groups, the present research has the Cohen's d effect size of 0.5 and statistical power of 0.95 , which was calculated using $\mathrm{G}^{*}$ Power statistical power analysis tool. During data collection that spans for 10 days from 17th April 2017 to 26th April 2017, there were in total 96 respondents $(N=$ 96). There were 29 males (30.2\%) 67 females (69.8\%) who participated in the study, which make up to a total of 96 participants.

\subsection{Quantitative Analysis}

Two-way analysis of covariance (ANCOVA) was used to test each of the hypotheses in the present study. The independent variables were brand familiarity (familiar and unfamiliar) and the levels of co-creation involvement (low, medium, high). Scores on cooking skills (CS) were administered prior to the commencement of the experiment were used as a covariate to control for individual differences. Preliminary checks were conducted to ensure that there is no violation on the assumptions of normality, linearity, homogeneity of variances, homogeneity of regression slopes, and reliable measurement of the covariate. The table below shows the results that test the hypotheses. 
Table 1: The Effect of Brand Familiarity and Levels of Co-creation Involvement Test of Hypotheses using Analysis of Covariance

\begin{tabular}{clcccc}
\hline Hypotheses & Variable & Mean Square & $d f$ & $\mathrm{~F}$ & $p$ \\
\hline H1 & Hedonic & 0.33 & 1 & 0.70 & 0.50 \\
H2 & Cognitive & 1.48 & 2 & 2.68 & 0.07 \\
H3 & Social & 0.25 & 2 & 0.49 & 0.62 \\
H4 & Personal & 1.01 & 2 & 1.95 & 0.15 \\
H5 & Pragmatic & 3.24 & 2 & 4.49 & $0.05^{*}$ \\
H6 & Economic & 1.09 & 2 & 1.31 & 0.28 \\
H7 & Loyalty & 0.23 & 2 & 0.36 & 0.70 \\
\hline
\end{tabular}

Covariate: Cooking Skill

*p $<0.05$

The table above shows the ANCOVA results to test the effect of brand familiarity and the levels of co-creation involvement as the independent variables on each of the dependent variables. Of all the hypotheses tested, only $\mathrm{H}_{5}$ was supported, where there was a significant effect of brand familiarity and the levels of co-creation involvement on pragmatic experience after controlling for cooking skills, $\mathrm{F}(2,89)=4.49, p=0.01$, with a small effect size (partial eta squared $=0.09$ ). Descriptive analysis of the dependent variable was then conducted based on the mean and standard deviation for each of the experimental groups. Participants in the familiar brand and medium co-creation level of involvement reports the highest in pragmatic experience compared to all other groups $(\mathrm{M}=4.06, \mathrm{SD}=0.66)$.

\section{Discussion}

The aim of this research is to find out the effect of brand familiarity, experience, and loyalty on value co-creation process. The interaction effect from the analysis of covariance (ANCOVA) of familiarity and the levels of co-creation involvement on pragmatic experience showed a significant effect $(p=0.014)$, which is one of the dimensions that form the overall customer experience. There was no significant effect found on other dimensions of experience and loyalty, however. This finding calls for attention as it suggests that the participants who took part in the online experiment had effect only on the pragmatic experience dimension that contributes toward the overall experience concept that was conceptualised by Stokburger et al. (2016).Pragmatic experience refers to the practical benefits that co-creators would be receiving upon participating in the activity. This appears to be in-line with the pragmatic reasoning schemas as proposed by Cheng, Holyoak, Nisbett and Oliver (1986) which suggests that people typically reason the consequences of their behaviour using abstract knowledge system that is structured in pragmatic fashion.

In addition, it has been found that participants in the familiar brand and medium level of cocreation (FM) group were responding to most of the dependent variables, which are hedonic, cognitive, personal, pragmatic, and loyalty. This finding suggests that customers would be more willing to moderately contribute their resources to a familiar brand compared to unfamiliar brand.

The present study contributes to the discussion of value co-creation from the perspective of S-D logic which emphasizes that value is contributed by the consumers and that service should be viewed as the unit of exchange (Vargo \& Lusch, 2004). Inline with the consumercentric perspective that is echoed by the integrated marketing communication researchers, customers are demanding for more active role in production. In order to fulfill this emerging shift of consumerism, marketers are forced to be more receptive of customers' active participation that in turn creates value for them (Saarijarvi et al., 2013). As consumption is viewed as a production process, firms are discouraged to act instinctively, but with distinctive development of skills among the co-creators that would drive firm's success (Firat, Dhokakia, \&Venkatesh, 1993). Beneficial input of knowledge should be included in the process of value creation, apart from one's expertise and competency (Zolkepli, 2016; Vargo \& Lusch, 2004). The postmodern view of marketing argues that a created product 
should not be regarded as the end-process of a product as customers are the one who will be determining the contribution towards the value of a firm's business, be it tangible or intangible ones (Saarijarvi, 2013).

As this study shows the interaction between brand familiarity and the levels of co-creation involvement have effect on the pragmatic experience, it is implied that the co-creators often are considering the benefits that they get in return for their exchange of resources upon participating in a call to action. In this regard, a form of pragmatic experience should be achieved in a successful co-creation approach.

Although this study manages to find that the differences in the levels of co-creation along with the intervention of brand familiarity does have an impact on a dimension of experience, it however, did not manage to empirically find statistical relevance of each levels of cocreation involvement that lead to conclude the optimum point of co-creation level due to the methodology and analysis used. Previous study carried out by Stokburger et al. (2016) has concluded that the optimum point of success was in the medium level of involvement as moderated by the effects of self-efficacy and process enjoyment. In determining the levels of co-creation involvement co-creation in pizza making, the present study determines from the stages of difficulty from sources that might be unfamiliar in creating the product. In order to counter such limitation, rigorous pretest is suggested to be applied in the following inputs from a panel of expert views, preferably the ones who are familiar in the kitchen setting of a food and beverage setting. Furthermore, the complexity of Bayesian model analysis used by Stokburger et al. (2016) is suggested to be adopted as an avenue of consideration for further study. In addition, the present study is not able to replicate the findings that are reported in the previous study by Kerleye (2016), which found a significant difference on the overall experience of the customers. A more stringent sampling methodology that takes into consideration the participants' role readiness, which include their motivation, clarity and ability should be implemented in the further study (Kerleye, 2016). Although the present study recruited participants from the real world setting that provides a higher variability of responses, the sample size is rather humble-scaled during the data collection that was carried out in the duration of one week.

\section{Conclusion}

This study is one step ahead in uncovering in the context of the Malaysian market in the food and beverage setting, although it has been argued against the implementation due to lack of demand and technology readability (Arshad et al., 2013). This study has investigated the effects of brand familiarity and the levels of co-creation on customer experience and loyalty in the context of crowdsourcing engagement. Value co-creation that builds on the understanding of SD Logic which is deemed as the emergence and transcendence of knowledge in marketing management has shown that customers are seeking for active role in contributing to the output of a business process that leads to firm's business success. Such notion marks the shift of consumerism emphasizes on the need for marketers and researchers to understand the source of motivation in the context of crowdsourcing engagement that benefits the stakeholders involved, including the customers, employees and shareholders. In the context of food and beverage which is deemed as one of the emerging business sectors that witness high occurrence of crowdsourcing engagement, it has been found that the interaction of brand familiarity and the levels of co-creation involvement has effect on pragmatic experience for the customers. The result has the implication for firms to further understand such dimension of experience that form the overall customer experience which would further lead to loyalty. It is also interesting to note in the present study which finds that familiar brands has higher success rate in a crowdsourcing engagement approach. Therefore, for firms to gain the intended success in the approach of crowdsourcing engagement, greater brand awareness is recommended to achieve in its initial stage of business model. Possible avenues for further research may consider the factors of generalizability and conclusivity of the dimensions of experience and loyalty. 


\section{Acknowledgement}

This research is funded by Universiti Sains Malaysia and Ministry of Higher Education Malaysia under Fundamental Research Grant Scheme (FRGS) 203.PCOMM.6711488

\section{Reference}

i. $\quad$ Aaker, J., 1997. Dimensions of Brand Personality. J. Mark. Res, 34(3), pp. 347-356.

ii. Agafonovas, A. \& Alonderienè, R., 2013. Value Creation in Innovations Crowdsourcing. Example of Creative Agencies, 4(17), pp. 72-104.

iii. Alba, J. W. \& Hutchinson, J. W., 1987. Dimensions of consumer expertise. J. Consum. Res, 13(4), pp. 411-454.

iv. Andrine, B. \& Solem, A., 2015. Influences of customer participation and customer brand engagement on brand loyalty. J. Consum. Mark., 33(5), pp. 332-342.

v. Arshad, N. H. et al., 2014. Issues and Challenges in Crowdsourcing Platform Implementation in Malaysia. Proc. 13th Int. Conf. Appl. Comput. Appl. Comput. Sci., pp. 95-100.

vi. Bauer, R. M. \& Gegenhuber, T., 2015. Crowdsourcing: Global search and the twisted roles of consumers and producers. Organization, 22(5), pp. 661-681.

vii. Brabham, D. C., 2008. Crowdsourcing as a Model for Problem Solving: An Introduction and Cases. Converg. Int. J. Res. into New Media Technol, 14(1), pp. 75-90.

viii. Carbonell, P., Rodriguez-Escudero, A. I. \& Pujari, D., 2009. Customer Involvement in New Service Development: An Examination of Antecedents and Outcomes. J. Prod. Innov. Manag, 26(5), pp. 536-550.

ix. Dijk, J. v., Antonides, G. \& Schillewaert, N., 2014. Effects of co-creation claim on consumer brand perceptions and behavioural intentions. Int. J. Consum Stud, 38(1), pp. 110-118.

x. $\quad$ Ericsson, K. \& Smith, J., 1991. Toward a general theory of expertise. Cambridge: Cambridge University Press.

xi. Firat, A. F., Dholakia, N. \& Venkatesh, A., 1993. Marketing in Postmodern World. Eur. J. Mark, 29(1), pp. 40-56.

xii. France, C., Merrilees, B. \& Miller, D., 2015. Customer Brand Co-creation: A conceptual model. Mark. Intell. Plan., 36(6), pp. 848-864.

xiii. Grönroos, C., 2006. Adopting a service logic for marketing. Mark. Theory, 6(3), pp. 317-333.

xiv. Hansen, A. V., 2017. What stories unfold: empirically grasping value co-creation. Eur. Bus. Rev., 29(1), pp. 2-14.

xv. Homburg, C. \& Kuehnl, C., 2014. Is the more always better? A comparative study of internal and external integration practices in new product and new service development. J. Bus. Res, 67(7), pp. 1360-1367.

xvi. Jacoby, J., Troutman, T., Kuss, A. \& Mazursky, D., 1986. Experience and expertise in complex decision making. Adv. Consum. Res, Volume 13, pp. 469-472.

xvii. Jahn, B. \& W. Kunz, 2012. How to transform consumers into fans of your brand. J. Serv. Manag, 23(3), pp. 344-361.

xviii. Jeff, H., 2006. The Rise of Crowdsourcing, s.l.: Wired.

xix. Keller, K. L., 2003. Brand Synthesis: The Multidimensionality of Brand Knowledge. $J$. Consum. Res, 29(4), pp. 595-600.

xx. Kennedy, E. \& Guzmán, F., 2016. Co-creation of brand identities: consumer and industry influence and motivations. J. Consum. Mark, 33(5), pp. 313-323. 
xxi. Kristal, S., Baumgarth, C., Behnke, C. \& Henseler, J., 2016. Is co-creation really a booster for brand equity? The role of co-creation in observer-based brand equity (OBBE). J. Prod. Brand Manag, 25(3), pp. 247-261.

xxii. Lee, C. K. M. et al., 2015. Explore the feasibility of adopting crowdsourcing for innovative problem solving. Ind. Manag. Data Syst, 115(5), pp. 803-832.

xxiii. Lin, Y., 2013. Evaluation of co- branded hotels in the Taiwanese market: the role of brand familiarity and brand fit. Int. J. Contemp. Hosp. Manag, 25(3), pp. 346-364.

xxiv. Maddux, C. D. \& Johnson, D. L., 2012. The Semantic Web-Its Role As an Aid to Data Integration. Comput. Sch, Volume 29, pp. 1-5.

xxv. Majchrzak, A. \& Malhotra, A., 2013. Viewpoint: Towards an information systems perspective and research agenda on crowdsourcing for innovation. J. Strateg. Inf. Syst, pp. 257-268.

xxvi. Marjanovic, S., Fry, C. \& Chataway, J., 2012. Crowdsourcing based business models: In search of evidence for innovation 2.o. Sci. Public Policy, 39(3), pp. 318-332.

xxvii. McColl-Kennedy, J. R., Cheung, L. \& Ferrier, E., 2015. Co-creating service experience practices. J. Serv. Manag, 26(2), pp. 249-275.

xxviii. Muniz, A. M. J., O'Guinn, C. \& Thomas, 2001. Brand Community. J. Consum. Res., 27(4), pp. 412-432.

xxix. Oyner, O. \& Korelina, A., 2016. The influence of customer engagement in value cocreation on customer satisfaction: Searching for new forms of co-creation in the Russian hotel industry. Worldw. Hosp. Tour. Themes, 8(3), pp. 327-345.

xxx. Saarijarvi, H., Kannan, P. K. \& Kuusela, H., 2013. Value co- creation: theoretical approaches and practical implications. Eur. Bus. Rev., 25(1), pp. 6-19.

xxxi. Srinivasan, S. S., Anderson, R. \& Ponnavolu, K., 2002. Customer loyalty in e-commerce: an exploration of its antecedents and consequences. J. Retail., Volume 78, pp. 41-50.

xxxii. $\quad$ Stokburger-Sauer, N., Scholl-Grissemann, U., Teichmann, K. \& Wetzels, M., 2016. Value cocreation at its peak: the asymmetric relationship between coproduction and loyalty. J. Serv. Manag., 27(4), pp. 619-651.

xxxiii. Tam, J. L. M., 2008. Brand familiarity: its effects on satisfaction evaluations. J. Serv. Mark. , 22(1), pp. 3-12.

xxxiv. Vargo, S. L. \& Lusch, R. F., 2004. Evolving to a New Dominant Logic for Marketing. J. Mark., 68(1), pp. 1-17.

xxxv. Vargo, S. L. \& Lusch, R. F., 2008. Service-dominant logic: Continuing the evolution. J. Acad. Mark. Sci., 36(1), pp. 1-10.

xxxvi. Vargo, S. L., Maglio, P. P. \& Akaka, M. A., 2008. On value and value co-creation: A service systems and service logic perspective,. Eur. Manag. J, 26(3), pp. 145-152.

xxxvii. Vega-Vazquez, M., Revilla-Camacho, M. Á., Cossío-Silva, F. J. \& Cossı, F. J., 2013. The value co-creation process as a determinant of customer satisfaction. Manag. Decis, 51(10), pp. 19451953.

xxxviii. Verleye, K., 2015. he co-creation experience from the customer perspective: its measurement and determinants. J. Serv. Manag., 26(2), pp. 321-342.

xxxix. Xu, Y., Ribeiro-Soriano, D. E. \& Gonzalez-Garcia, J., 2015. Crowdsourcing innovation and firm performance. Manag. Decis, 53(6), pp. 1158-1169.

xl. Zhihong, L., Hongting, T. \& Yanhong, Z., 2015. Research on the Driving Factors of Customer Participation in Service Innovation in a Virtual Brand Community. Int. J. Innov. Sci, 7(4), pp. 299-309.

xli. Zolkepli, I. A., 2016. Changing Consumer Culture in the Wake of Web 3.o: Mobilizing Online Crowd Competency and Expertise Through crowdsourcing. s.l., Proceedings of the 3rd European Conference on Social Media (ECSM). 